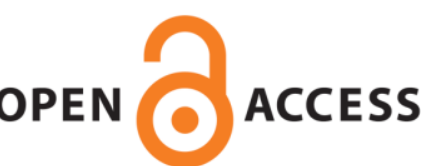

UWS Academic Portal

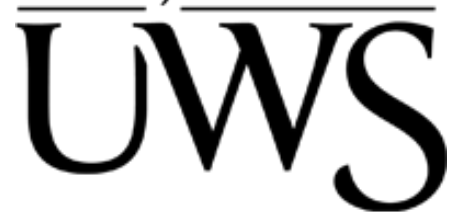

\title{
Decision support criteria and the development of a decision support tool for the selection of conservation materials for the built cultural heritage
}

Turk, Janez ; Mauko Pranjić, Alenka; Hursthouse, Andrew; Turner, Robert; Hughes, John

Published in:

Journal of Cultural Heritage

DOI:

https://doi.org/10.1016/j.culher.2018.10.001

Published: 01/05/2019

Document Version

Peer reviewed version

Link to publication on the UWS Academic Portal

Citation for published version (APA):

Turk, J., Mauko Pranjić, A., Hursthouse, A., Turner, R., \& Hughes, J. (2019). Decision support criteria and the development of a decision support tool for the selection of conservation materials for the built cultural heritage. Journal of Cultural Heritage, 37, 44-53. https://doi.org/10.1016/j.culher.2018.10.001

\section{General rights}

Copyright and moral rights for the publications made accessible in the UWS Academic Portal are retained by the authors and/or other copyright owners and it is a condition of accessing publications that users recognise and abide by the legal requirements associated with these rights.

Take down policy

If you believe that this document breaches copyright please contact pure@uws.ac.uk providing details, and we will remove access to the work immediately and investigate your claim. 


\section{DECISION SUPPORT CRITERIA AND THE DEVELOPMENT OF A DECISION SUPPORT TOOL FOR THE SELECTION OF CONSERVATION MATERIALS FOR THE BUILT CULTURAL HERITAGE}

Janez Turk $^{1}$, Alenka Mauko Pranjić ${ }^{1}$, Andrew Hursthouse ${ }^{2}$, Robert Turner ${ }^{3}$ and John J. Hughes $^{4 *}$

${ }^{1}$ Slovenian National Building and Civil Engineering Institute, Dimičeva ulica 12, 1000 Ljubljana, Slovenia, janez.turk@zag.si, alenka.mauko@zag.si

${ }^{2}$ School of Science and Sport, University of the West of Scotland, Paisley Campus, PA1 2BE, Scotland, Andrew.Hursthouse@uws.ac.uk

${ }^{3}$ Eura Conservation Ltd, Halesfield 19, Telford, Shropshire, England.

Robert.Turner@eura.co.uk

${ }^{4}$ School of Engineering and Computing, University of the West of Scotland, Paisley Campus, PA1 2BE, Scotland, john.hughes@uws.ac.uk

*Corresponding Author

\section{Abstract}

Significant criteria for choosing materials (consolidants and protective coatings) for the conservation of the built cultural heritage were gathered from the literature and by consultation with experts working on the preservation of cultural heritage. Ten criteria were chosen from these, and a questionnaire was prepared and sent to stakeholders in the cultural heritage conservation domain in order to evaluate, score and rank the importance of the proposed criteria. Based on the results obtained a decision support tool was developed, aimed at conservators and other stakeholders, to help them to make sustainable decisions with regard to the selection of conservation materials for treatment of the built cultural heritage. Performance characteristics and health and safety were identified to be the most important criteria. A preliminary decision can be made based on these two criteria, however, reversibility, minimum intervention and re-treatability are also of very high importance and additional information about these characteristics of the material are required to support decisions. Information about environmental performance, peer recommendation, the application techniques, the price and availability of the materials, which are also integrated in decision-support tools, can help conservators and stakeholders to reach a final decision on interventions. The study also provides 
feedback for the manufacturers of conservation materials. For the users of material, it is very important that the manufacturers clearly identify key characteristics (i.e. criteria) on the product, including those related with environmental performance of the materials.

Keywords: cultural heritage, criteria evaluation, questionnaire, decision tool, consolidants, preservatives.

\section{INTRODUCTION}

Cultural heritage is an important legacy of past societies, which requires careful maintenance. The transfer of past knowledge and tradition to future generations constitutes an important shared thread connecting different cultures. Cultural heritage also plays a critical role in education and leisure for all generations, past, present and future (Williams, 2009). Taking care of cultural heritage and investing in its preservation improves our quality of life, and enhances economic and human resources that influence the growth of society (Di Pietro et al., 2015), generally taken to be a common, positive, public good.

Many historical buildings and structures are built of stone. Like all historic materials, stone undergoes gradual, episodic and cyclic deterioration when exposed to the effects of weather (Doehne and Price, 2010 and references therein, Douglas-Jones et al., 2016). The preservation of stone heritage is a delicate and complex challenge. Multiple variables have to be taken into account to identify the problems, define the necessary conservation actions to select the materials and procedures to be used (Giove et al., 2011; Sierra-Fernandez et al., 2017). Many national and international organizations take care of the maintenance and preservation of cultural heritage to protect it for subsequent generations. Management of cultural heritage is therefore a multi-disciplinary process, which requires the cooperation of several groups of 
experts such as conservators, architects, art historians, scientists, public government representatives and owners of cultural heritage assets (Muñoz Viñas, 2011). Such management includes not only continuous conservation and restoration works, but also development of protection policies and strategies, analyses of the effects of protection and the formulation of protection standards and requirements. While professionals (mainly in technical and scientific activities) take part in practical conservation and restoration works, experts from other disciplines contribute with their knowledge to prepare laws and management guidelines (Doehne and Price, op cit.; Kioussi et al., 2013). Within this decision making environment, complex competing agendas exist as different actors have different perspectives and objectives. For this reason, it is important that any decision making process is based on collective learning among different actors, involving compromise as a crucial step in the process. This approach is preferred to traditional decision making processes based on financial and economic feasibility analysis alone. The traditional process considers only a limited group of experts and too few quantitative variables, meaning that it is not able to cope with comprehensive and complex problems, that the preservation of cultural heritage undoubtedly is (Ferretti et al., 2014).

A key question for practical conservation is how to select from the, mostly commercially, available materials for consolidation and other preservation actions (such as self-cleaning, biocides, water repellents, surface compensation mortars etc.), in order to improve sustainability in cultural heritage protection? Stone treatments with lime, barium hydroxide, organic polymers, alkoxysilanes, epoxies, acrylics and other materials are widely used (Doehne and Price, op cit.). For these, there are crucial requirements to be met for the specification of these materials, which are widely accepted among heritage stakeholders (see e.g. Sasse and Snethlage, 1997). Any applied consolidative or preservative material should be compatible with the treated stone in order to avoid internal stresses and it should be completely invisible. 
Moreover, treatment needs to be reasonably cheap, easy to apply and safe to handle (Doehne and Price, op cit.).

Because many commonly used consolidative/preservative materials fail to satisfy these requirements, and are therefore not effective, new nano-particle based materials are continuously being developed, due to their favourable characteristics meeting many of the above mentioned requirements. Conservation materials need be effective, but attention should also be given to their sustainability and their impact on the environment and the health of workers (Balliana et al., 2016). However, untill recently, the environmental issues surrounding production and use of these materials have been mostly neglected, except of course in terms of regulatory compliance. Consumption of resources and emissions released into the environment at all stages of the life cycle of the product can be evaluated by means of Life Cycle Assessment (LCA) methods. This allows the assessment of environmental impacts of the product in a range of different environmental categories such abiotic depletion of mineral and fossil resources, global warming (presumably associated with greenhouse gas emissions), eutrophication (associated with $\mathrm{SO}_{2}$ kg equiv. emissions), toxicity (1,4-dichlorobenzene kg equiv. emissions) and others (Blundo et al., 2014). Environmetal performance of a product is specified in Environmental Product Declaration (EPD), which is a standardized way of quantifying the environmental impact of a product. Concerning global environmental problems, LCA has been commonly applied in the building and construction sectors for decades, while only a few holistic LCA studies exist for conservation of immovable cultural heritage (Ferrari et al., 2015; Turk et al., 2017; Mauko et al., 2018). Environmental imapct assessment of conservation materials is important also because their production can contribute to greenhouse gas and sulphur dioxide emissions that indirectly contribute to the degradation of cultural heritage (Reyes et al., 2011). Technicians (conservators, scientists etc.) who work with different 
materials in various conditions of application, may be exposed to risks of a chemical, physical and microbiological nature (Blundo et al., 2014). Considering the use of nano-materials, special attention should be given to the potential threat to health related to the toxicity of nano-particles (cf. Elsaesser and Howard, 2012). Safety (i.e. the environmental and human health harmlessness of conservation materials) is thus a crucial criterion that should be considered for sustainable protection of cultural heritage, but that to date is not often considered over the long term of application that is required for heritage.

\section{RESEARCH AIM}

The aim of this study was to propose and evaluate significant criteria related to the choice of consolidative and preservative treatment materials that are used for the protection of built cultural heritage. Taking into account the significance of various criteria, a decision support tool is proposed to help conservators and other stakeholders to improve sustainable decision making with regard to the selection of consolidative and preservative materials for treatment of the built cultural heritage. We report on the results of a consultation process which provides a partial map of the decision making landscape in this particular aspect of cultural heritage conservation.

\section{METHODS}

Initially, the literature was consulted to establish the most representative criteria and requirements which are, or should be, taken into account before applying consolidant and preservative materials to built historical assets (Clifton, 1980; Fidler, 2004; Martelli Castaldi, 2007; Karatasios et al., 2009; Doehne and Price, 2010; Van Saaze, 2013; Andreotti et al., 2018). Requirements imposed by internationally agreed conservation charters were also taken into account (ICOMOS 1964, de Naeyer et al., 2000). In addition, consultations were held with 
conservators and other stakeholders to establish a commonly agreed set of criteria. These were experts from Slovenia, Serbia and the United Kingdom, who collaborated in the HEROMAT FP7 project "Protection of cultural heritage objects with multifunctional advanced materials". After considering their experiences and suggestions, ten apparently important criteria were collected (see Table 1).

Authenticity is also often mentioned in the literature, as an important criterion for conservation of built cultural heritage (de Naeyer et al., 2000; Doganer and Dupont, 2013, Douglas-Jones et al. 2016). Authenticity is defined as the degree to which a historic site and its surrounding context convey information about the past honestly and accurately. Authenticity is often discussed alongside integrity (Doganer and Dupont, 2013). As authenticity is relatively difficult to evaluate, in this study the preference was given to the other criteria, as listed in Table 1. Amongst other criteria, which could potentially be considered as relatively important, but were not discussed in this study, are ease-of-use and shelf-life of conservation materials. However, these two criteria are rarely mentioned in the literature (cf. Fuentes et al., 2015), and commonly,, conservation materials often have an indefinite shelf-life (Appelbaum, 2007).

In order to independently evaluate the relative importance of the ten criteria and to obtain meaningful data, a questionnaire was prepared to elicit responses from the expert community. The questionnaire was then delivered to the international public of practitioners in cultural heritage conservation, who represented a wide range of expertise. The goal of the questionnaire was to gather opinions from a representative number of this expert and targeted public.

From the results, a decision support tool was subsequently developed that aimed to serve stakeholders of built cultural heritage, especially conservators, but also scientists, heritage 
owners, architects, engineers, planners, museum professionals and other experts, to take sustainable decisions with regard to the selection of conservation materials. It needs to be emphasised that the tool developed is intended to support decisions, not to make them. The final decision on the choice of the conservation material to be used in a treatment regime is ultimately made by the responsible managers, be they conservators, scientists or architects. The tool is intended to assist the gathering of information on key criteria, that are themselves determined from consultation of literature and by prioritisation by experts through the questionnaire. It ensures that rational decisions can be made based on available material information that addresses specific criteria that the community of expert stakeholders consider to be the most significant in choosing a conservation treatment material.

\subsection{The criteria, and their definitions}

The criteria selected for the questionnaire are listed and randomly ranked in Table 1, with appropriate explanations. These possible definitions were not shared with the public that was consulted, so as not to bias their input.

\subsection{Evaluation of criteria}

The criteria were evaluated by heritage stakeholders/practitioners from different countries, who took part a questionnaire-based survey. The questionnaire was placed on the internet in order to allow ease of access and to achieve an international participation. Participation was encouraged through the use of professional on-line networks and personal contacts. Each participant/respondent was asked to indicate his role/position and country of residence. Then participants were asked to score, and rank the ten criteria described in Table 1 . The first question (Question 1 in Table 2) asked was "Score each of the listed criteria according to their level/degree of importance”. Respondents scored the criteria with values from 1 to 5 , where 1 
meant that respondents strongly believed the criterion is not important and 5 meant that respondents strongly believed the criterion is important. Then respondents were asked to place the criteria in a ranked order (Question 2 in Table 2); "Rank the criteria from 10 to 1 (10 - the most important, 1 - the least important)”.

Altogether, 205 respondents took part. Among the target audience, conservators prevailed - 75 respondents (37\%), followed by scientists - 55 respondents (27\%) and engineers - 17 respondents (8\%). Respondents from other audience groups took part in low numbers, 11 or less in each of the rest of the group (see Table 2).

Among the 205 respondents who answered to the first question, 147 (72\%) continued with fulfilling the survey to answer also the second question, to rank the criteria (conservators - 49 respondents (33\%), scientists - 38 respondents (26\%), engineers - 10 respondents (7\%), members of the public -9 respondents (6\%), architects -7 respondents (5\%), visitors -5 respondents (3\%), museum professionals -4 respondents (3\%) and other -25 respondents (37\%)) (Table 2).

\section{RESULTS AND DISCUSSION}

\subsection{Scoring the criteria according to level/degree of importance}

The criteria were scored as indicated in Fig. 1. An average score value above 4.5 meant that respondents strongly believed that a criterion was important. Taking into account analysis of all 205 responses (from all target groups), two criteria were recognized as strongly important: performance characteristics and health and safety. The rest of the 8 criteria were evaluated with 
an average score values between 3.5 and 4.5, meaning that respondents mildly believed that the criteria were important (Fig. 1).

However, the results can be analyzed also by groups of respondents (i.e. their position/role). Conservators and scientists are the two most important groups, as they took part in this survey in the largest number (Table 2). It means that their opinion is most strongly reflected in the overall results. Members of other groups take part in this survey in relatively small numbers only (Table 2).

Conservators, who took part in the greatest number (36\% of participants) consider an additional three criteria as strongly important: re-treatability, minimum intervention and reversibility (the average score values are slightly above 4.5, Fig. 1b). Taking into account all respondents (alse scientists and other groups of heritage practitioners), the average score values of these three criteria dropped below 4.5, meaning that they are classified as mildly important (Fig. 1a).

Of conservators, $89 \%$ strongly believed that performance characteristics are an important criteria (score value 5) and 10\% mildly believe performance characteristics are important (score value 4). Scientists scored similarily, $87 \%$ strongly believed that this criterion is important and 7\% mildly believed that this criterion is important. With regard to health and safety, $71 \%$ of conservators scored it at 5 and $23 \%$ at 4 . For scientists, $65 \%$ evaluated this criterion with a score value of 5 and $29 \%$ with a score value of 4 .

No respondents chose any option giving a score of below 3 to any of the criteria in the entire set of responses, suggesting that every criteria offered for consideration was considered significant (“unsure of importance of criterion” (average score 2.5 - 3.5), “mildly believe 
criterion is not important" (average score 1.5 - 2.5), or "strongly believe criterion is not important” (average score < 1.5)) (see Fig. 1).

Price and availability were scored with the lowest score values of all criteria (average scoring 3.87 and 3.61), but are still believed to be "mildly important". Conservators and scientists scored availability with relatively higher values, (score values from 3 to 5), while other groups of heritage practitioners (engineers, architects, members of the public), who take part in this survey in relatively lower number, scored this criterion with relatively low values (score values 3 and 2).

\subsection{Ranking the criteria according to their relative importance}

Despite the fact that all the proposed criteria were recognized to be important, respondents were asked to rank the criteria from relatively the most important to relativelyless important in next part of the survey. In accordance with the first question, performance characteristics and health and safety were ranked in first and second place and availability was placed in last place (Fig. 2). Interestingly, some of the other criteria were scored in a different way, as expected from results obtained from the first question.

\subsubsection{Criteria preferences among groups of stakeholders}

Performance characteristics were recognized as a top priority criterion among conservators, scientists, architects and also engineers. This criterion was ranked at second or third position also among some other groups such as visitors, industry practitioners and heritage managers. However, the numbers of respondents in the latter groups was low (Fig. 3). Museum professionals (four respondents only) consider this criterion as the least important one among proposed ten criteria. 
However, the most relevant information is that of conservators and scientists, who participated in the highest number in the survey (49 conservators answered to the question and 38 scientists) (Table 1). For the conservators, the most important criterion is undoubtedly performance characteristics, followed by reversibility. The criteria health and safety, minimum intervention, re-treatability and peer recommendation belong to a third group, as their average ranking is similar. Application technique and environmental impact are relatively less important criteria for conservators (average ranking of both criteria is almost identical), while price and availability are relatively the least important of all ten proposed criteria (Figs. 2b and 3).

Scientists have quite similar preferences with regard to the top three priority criterion, however in contrast with conservators, they ranked health and safety above reversibility (Figs. 2c and 3). The consensus about the highest importance of these three criteria among the scientist is clear. All other criteria gained significantly lower average ranking values, though an exception may be environmental impact, which is somewhere in the middle considering the average ranking value (Fig. 3).

An important difference among scientists and conservators is in the perception of re-treatability. This is an important criterion for conservators (having also relatively high average ranking value, i.e. 6). Scientists consider this criterion together with availability as relatively the least important (average ranking 3.8). A difference in perception of minimum intervention, environmental impact and price is also evident (Figs. 2b, c and 3).

Considering the preference of all respondents (147) that responded to the criteria ranking exercise, the three most important criteria remain the same as for conservators and scientists 
(both these two groups of stakeholders present $60 \%$ of respondents). Also in such a case, availability is recognised as relatively the least important criterion. Differences in average ranking of six other criteria is relatively low, especially among environmental impact, price and re-treatability having practically the same average ranking value (i.e. 4.7 to 4.8) (Figs. 2a and $3)$.

\subsubsection{Influence of national perception on criteria preferences}

Answers obtained by conservators and scientists were additionally analysed to see if any significant differences occur between the countries from where these stakeholders originated.

Conservators from 16 countries took part in the survey. Most of them were from the United Kingdom (UK) (31) and from the United States of America (USA) (12), while only one to three respondents were from each of other fourteen countries. For this reason, only the information obtained from conservators coming from the UK and the USA can be statistically compared. The most evident difference among the conservators from the UK and the USA is the perception of the re-treatability criterion. Being recognized as the third most important criterion among conservators from the UK (average ranking 6.5) it has significantly less importance among conservators from the USA (average ranking 4.4) (Fig. 4). Consequently, conservators from the USA ranked six other criteria with higher values than conservators from the UK. It is also worth mentioning that conservators from the USA consider price as a relatively more important criterion than application technique, environmental impact and availability, while conservators from the UK have a different opinion. Conservators from the USA ranked all these three for them as relatively less important criteria with almost identical values (3.2 to 3.3 - taking into account the average value of ranking) (Fig. 4). Conservators from the UK and the USA 
presented $88 \%$ of all conservators who took part in the survey. For this reason, the average ranking preferences of all 49 conservators reflect mostly their preferences.

The number of scientists from specific countries, who took part in the survey, was low. The largest national group of scientists was from Italy (17), followed by Slovenian scientists (11) and scientists from UK (6). Only one to two scientists from another four countries took part in the survey, all together 38 scientists participated. The information obtained from scientists coming from Italy and Slovenia was statistically compared. Italian scientists ranked the health and safety criterion as relatively the most important one (ranking value 9.1), while Slovenian scientists ranked this criterion in third position (with significantly lower ranking value 6.8) (Fig. 5). Interestingly, Slovenian scientists gave a much lower average ranking values also to other, otherwise recognised as relatively important criteria (reversibility and environmental impact/performance). On other hand, significant differences can be observed in the perception of importance of the peer recommendation criterion. It is recognized as relatively the least important among Italian scientists (average ranking value 3.1) and as the second most important among Slovenian scientists (average ranking value 7.5) (Fig. 5).

Taking into account the information obtained from six scientists coming from UK, their preferences are more similar to Slovenian scientists than to Italian scientists. However, they consider re-treatability as quite an important criterion, while Slovenian scientists placed it in last position and also Italian scientists place it among the relatively less important criteria (eighth position).

\subsubsection{Environmental impact as an influencing parameter}


In this study, special attention is given to the environmental aspects of conservation materials (associated with energy consumption, greenhouse gas and other emissions released during their life cycle). For this reason, multi-criteria analysis was conducted, to see how the environmental awareness of the stakeholders about environmental sustainability in the field of conservation of built cultural heritage influences their perception of the importance of other criteria. Stakeholders were grouped to five groups, depending how they score the environmental impact/performance criterion in the first question of the questionnaire.

The results show that the perception of relative importance of criteria among stakeholders with different opinion of environmental impact is quite similar; an exception is the opinion of stakeholders, who strongly believe that environmental impact is not an important criterion. However, only two respondents have such an opinion, meaning that this group is too small to be statistically relevant. The largest groups are those where respondents strongly believe this criterion is important (63) and mildly believe criterion is important (59). Also groups where respondents are unsure of the importance of the criterion (14 respondents) and mildly believe the criterion is not important ( 9 respondents) can be potentially considered as large enough a group to be included in a statistical interpretation.

The perception of the criterion of peer recommendation is significant. The perception among groups that consider environmental impact to be relatively less important is higher for this criterion than among groups that hold opinions that consider environmental impact to be relatively more important (Fig. 6). Those who are unsure of the importance of environmental impact ranked the peer recommendation in second place (average ranking 7.3), while those who strongly believe that environmental impact is an important criterion ranked peer recommendation on the eighth place (average ranking 4.4). Re-treatability and price are the 
criteria which have a negative trend of relative importance, as groups that consider environmental impact to be relatively less important consider re-treatability and price as more important criteria than groups who value environmental impact more. On the contrary, health and safety shows just the reverse trend (Fig. 6). However, it is expected that groups of stakeholders, who consider environmental impact to be important, believe that health and safety is also one of the most important criteria.

\subsection{Decision support tool}

Taking into account the results obtained in the survey (the evaluation of the proposed criteria), a decision support tool was developed. The tool is shown here in the form of tables, but it can be converted also to decision trees. It is intentionally simple and obvious to use, and not intended to be proscriptive for conservation workers. It means to assist in a comprehensive assessment of the important factors that were weighed by conservation professionals in our consultation survey.

Undoubtedly, performance characteristics should be considered first, when choosing among conservation materials, when deciding which conservation material to apply on built cultural heritage. Performance characteristics depend on the functionality of the specific material used. Considering built cultural heritage, practitioners in cultural heritage conservation usually deal with consolidative materials or preservative materials, sometimes applied in the form of protective surface coatings. The main performance characteristics of consolidants are depth of penetration, viscosity, density, $\mathrm{pH}$, durability, compatibility with substrate and chemical compatibility, as indicated in Table 3. For coatings (e.g. with self-cleaning and/or self-healing properties), the important characteristics are similar, but can be reduced to five main parameters (viscosity, density, $\mathrm{pH}$, durability, compatibility with substrate). 
Stakeholders, especially conservators, are interested in these parameters, when deciding whether to use treatment materials, and for this reason, the manufacturers should label these parameters on their products, if possible. Manufacturers should also consider technical steps (testing etc.) to provide information that answers such questions, again if at all possible.

In the context of health and safety there should also be a consideration of the eventual toxicity of consolidative/preservative materials indicated in material safety data sheet (MSDS). Hazardous substances and their flammability should also be clearly labeled in MSDS, so the user can be aware of potential threats, and to allow a worker to decide what kind of personal protective equipment to wear (such as dust mask, respirator, chemical-resistant gloves, chemical safety goggles etc.). Taking into account performance and safety characteristics of materials in MSDS (see also Tables 3 and 4), stakeholders can make a rational selection between those available on the market.

Following our stakeholder-prioritised list, the next three criteria considered should be the potential reversibility, minimum intervention and re-treatability of the products being considered for use. Stakeholders need to know if the new material used in a conservation intervention is reversible, is it possible to apply it on the object observing the principles of minimum intervention, and is a subsequent application of another consolidant/preservative possible (re-treatability, or ability for reapplication to maintain the intended protective function) (Table 5)?

Stakeholders also need access on the environmental footprint of the material that are proposed for application (Table 6). Does the product have the Environmental Product Declaration (EPD), 
for example? Environmental impact/performance of the product is evaluated in EPD for different Life Cycle stages: the product stage (raw material production and their transport to the factory, production of the conservation material in the factory), the construction process stage, the use stage and eventually end-of-life stage. Several impact categories are usually taken into account, so the user of this product can see what is the impact on Global Warming, Acidification, Eutrophication, Photochemical Oxygen Creation, Ozone Layer Depletion, Abiotic Depletion etc. Stakeholders can compare different products with regard to their environmental footprint/performance and preference can be given to more environmental friendly products.

If no Environmental Product Declaration is available for the product, the stakeholder would be at least interested in the amount of energy which is consumed to produce and apply the material and in the carbon footprint of the product, which is the most standard impact category, calculated for many products that are available in the market.

Peer recommendation is also an important part of the context of making a decision to use a material, or not. Naturally, any kind of past experiences with use of the protective materials are welcome, before making any decision about using the material. Basically, stakeholders may simply like to know if past experiences exist or not, and if they do exist, what are these experiences (advantages/disadvantages associated with use of the material) (Table 7). On other hand, the question can be also related to a choice between whether stakeholders in a specific case would prefer to use some relatively well tested and verified conservation materials (having some tradition in its use in protection of built heritage), or would they prefer to use innovative, advanced materials, which may not be properly tested in practice? 
Most of the consolidants/preservatives can be applied by spray gun, brush or roller. However, depending on the application method chosen, the consumption of the material may be different (Table 8). Consumption primarily depends on type of treated stone/substrate (i.e. its porosity), but also on losses to the surrounding environment. Losses are usually greater for spray gun application. Moreover, different application techniques have different effect on some of the criteria discussed here. For example, the greater the losses during treatment, the greater the relative environmental impact associated with the conservation material will be, due to wastage. Greater loss usually means also higher costs, as larger quantities of material are required.

Moreover, spray gun application requires the use of electricity, that also affects environmental indicators (as electricity production is associated with emissions and often with consumption of non-renewable energy resources). On other hand, application with brush, or roller, is carried out manually.

Stakeholders would like also to know which diluter or solvent to use for cleaning of the equipment after the application of the material, or can cleaning be carried out simply with water? Materials, which can be washed with water to clean the brush/roller or spray, are preferable. Cleaning with solvent diluters may increase the environmental footprint associated with the treatment.

Finally, stakeholders may make the final decision based on the price of the material and its availability (Table 9). Can the prices of materials be significantly different? If yes, the price can have some role in the final decision. The cost of any special protection equipment and safety measures if required should also be accounted. The time required to get the product may not be really important, but considering a possible significant deviation with regard to the delivery 
time (months), this criterion may still play some role in decision making. However, if certain conservation material satisfies all requirements, but it is currently not available, it would probably be worth to wait for it even over relatively longer period (several months).

Taking into account the proposed decision support tool, some attention should be given tp the evaluation of the answers given (i.e. "Yes" and "No"). For the evaluation of performance characteristics of conservation materials, it is assumed that the functionality of conservation materials is associated either with surface protection or consolidation (see Table 3), meaning that the answer in relation to one of these two parameters will be "Yes". Similarly, it is assumed that also, when evaluating the application technique that theanswer "Yes" will be given at least for one type of proposed application technique (Table 8). A "No" answer does not have the same impact for the evaluation of the proposed criteria. If there is a "No" in relation to the criteria of "Reversibility", "Minimum intervention" "Re-treatability" (Table 5) and for one or more parameters under "health and safety" (Table 4), this means that the treatment has a negative impact/effect on the built heritage in terms of these criteria (i.e. the conservation/preservation material fails to satisfy criteria requirements). While a "No" answer in the case of "Environmental footprint" and "Peer recommendation" criteria (Tables 6 and 7) means that there is probably a lack of relevant data (i.e. the effect cannot be evaluated).

It is likely that in practice, data to allow an answer to be given for one, or more, criteria will be missing. For example, when comparing two conservation materials, relevant data on the environmental footprint can be missing for one of them. If both materials being compared exhibit similar characteristics regarding most of criteria, and the environmental performance of one material is good or at least fair and there is lack of any such data on the other material, the preference in selection can be given to the former material. 
Even if the availability was considered as the relatively less important of the ten proposed criteria, it may still be a prevailing criterion. For example, the lack of availability of conservation material means direct rejection the particular product. This scenario is not very likely, but possible.

\section{CONCLUSION}

In this study we have demonstrated how ten pre-determined criteria, related to decision making for choosing conservation treatments for the built heritage, were subjected to an evaluation by expert stakeholders.. Based on the classification and determination of the relative importance of the criteria, provided by those stakeholders, a decision support tool has been proposed to to assist in the choice of appropriate and sustainable conservation materials for the protection of built cultural heritage. The tool itself is not complex to work through, and encourages decision makers to access relevant information in a structured manner. Though the tool is simple to apply, the gathering of the required information may be more demanding in practice. However, the tool does not require all the criteria to be evaluated for a better informed decision to be arrived at.

Considering performance characteristics and health and safety data (which, according to our survey, are the two most important criteria for conservators and other stakeholders), a preliminary decision can be made as to which of the available conservation materials are the most suitable for treatment of a given heritage structure or object. The potential for reversibility, minimum intervention and re-treatability are also of key importance and additional information about the suitability of the materials should also be sought. Furthermore, information about 
environmental impact, performance, peer recommendation, application techniques, price and availability of the materials, which are also integrated in decision-support tools, can help conservators and stakeholders to make a final decision. By using such a decision-support tool, decision makers can more easily compare different conservation materials and, based on data shown in the supporting tables, select the most adequate/suitable materials for the treatment of any given item of cultural heritage. However, the treatment of cultural heritage requires knowledge not only of the materials used (as discussed in this study) but also of the meaning and protected value of the object that is going to be treated (cf. Wisse et al., 2005). The latter aspect is case specific and thus not dicsussed in this study.

The intended impact of the proposed use of the tool presented, or indeed any similar approach, is to improve the outcomes of conservation interventions, in terms of environmental impact, and durability of the applied solution. It also promotes an ethical approach to decision making, favouring choices on the lower end of environmental impact scale and on the higher end of application efficacy. In taking into account peer reccommendation, and evidence based decisions, it promotes a responsible, experientially based approach to choosing materials. It can also be argued that is may encourage better record keeping, important for future conservation actions and for the accountability for practitioners’ actions.

We make no specific generalisations about what type of treatment materials would, or should be favoured, in making choices for conservation

In conclusion, this study is aimed not only to stakeholders and practitioners of built cultural heritage, but also to manufacturers of conservation materials. Many products lack several specifications, especially those related with environmental impact/performance. For the users 
of the material, it is very important that the manufacturers clearly label all the characteristics and criteria discussed in this contribution, on the product, including those related to environmental footprint and the performance of the conservation materials. 


\section{Acknowledgements}

We would like to acknowledge the European Commission's financial support for the HEROMAT project (FP7/2011-2015, project reference: 282992).

The authors thank conservators involved in the HEROMAT project and others for their constructive advices.

The authors also acknowledge the financial support provided by the Slovenian Research Agency (Research Core Funding No. P2-0273). 


\section{REFERENCES:}

Andreotti, S., Franzoni, E., Fabbri, P., 2018. Poly(hydroxyalkanoate)s-Based Hydrophobic Coatings for the Protection of Stone in Cultural Heritage. Materials 11, 165, 1-26. https://doi.org/10.3390/ma11010165.

Appelbaum , B., 2007. Conservation treatment methodology. Elsevier ltd.

Balliana, E., Ricci, G., Pesce, C., Zendri, E., 2016. Assessing the value of green conservation for cultural heritage: positive and critical aspects of already available methodologies.

International Journal of Conservation Science 7/1, 185-202.

D.S. Blundo, A.M. Ferrari, M. Pini, M.P. Riccardi, J.F. Garcia, A.P. Fernandez del Hoyo, The life cycle approach as an innovative methodology for the recovery and restoration of cultural heritage, Journal of Cultural Heritage Management and Sustainable Development 4/2 (2014) 133-148. DOI 10.1108/JCHMSD-05-2012-0016

Clifton, J.R. 1980. Stone consolidating materials. A status report. http://cool.conservation-us.org/byauth/clifton/stone/

de Naeyer, A.; Arroyo, S.P.; Blanco, J.R., 2000. Principles for Conservation and Restoration of Built Heritage, The Charter of Krakow 2000. Bureau Krakow, Poland. http://smartheritage.com/wp-content/uploads/2015/03/KRAKOV-CHARTER-2000.pdf

Accessed 20 June 2018

Di Pietro L., Guglielmetti Mugion, R., Mattia, G., Renzi, M.F., 2015. Cultural heritage and consumer behaviour: a survey on Italian cultural visitors. Journal of Cultural Heritage Management and Sustainable Development 5/1, 60-79.

Doehne, E., Price, C.A. (eds), Stone Conservation: An Overview of Current Research. Second edition. Getty conservation institute, Los Angeles (USA), 2010 http://www.getty.edu/conservation/publications_resources/pdf_publications/pdf/stoneconserv ation.pdf

Doganer, S., Dupont, W., 2013. Cultural heritage tourism and authenticity: San Antonio Missions Historic District. In Brebbia, C.A. (ed.) Structural Studies, Repairs and Maintenance of Heritage Architecture XIII, WIT press, 15-27. doi:10.2495/STR130021.

Douglas-Jones, R, Hughes, J, Jones, S \& Yarrow, T, "Science, value and material decay in the conservation of historic environments," Journal of Cultural Heritage, 2016, 823-833, 10.1016/j.culher.2016.03.007

Elsaesser, A., Howard, V.C. 2012. Toxicology of nanoparticles. Advanced drug delivery reviews 64/2, 129-137. https://doi.org/10.1016/j.addr.2011.09.001

Ferrari, A.M., Pini, M., Neri, P., Bondioli, F., 2015. Nano-TiO2 Coatings for Limestone: Which Sustainability for Cultural Heritage?. Coatings 5, 232-245.

doi:10.3390/coatings5030232. 
Ferretti, V., Bottero, M., Mondini, G., 2014. Decision making and cultural heritage: An application of the Multi-Attribute Value Theory for the reuse of historical buildings. Journal of Cultural Heritage 15, 644-655.

http://dx.doi.org/10.1016/j.culher.2013.12.007

Fidler, J. 2004. Science and the historic environment: Stone Consolidants inorganic treatments. New research on inorganic solvents offer improved techniques for masonry conservation. Conserv Bull 45, 33-35.

Forster, A.M. 2010. Building conservation philosophy for masonry repair: part 2 “principles”. Structural Survey 28/3, 165-188. DOI 10.1108/02630801011058906

Fuentes, A., Gurung, U., Lhendup, T., Cheki, D., Tshering, P., 2015. Locally and historically sourced strategies for conservation at the department of culture, Bhutan. Bulletin of the Australian Institute for the Conservation of Cultural Material 36/1, 23-32. https://doi.org/10.1179/0313538115Y.0000000006.

Giove, S., Rosato, P., Breil, M., 2011. An Application of Multicriteria Decision Making to Built Heritage. The Redevelopment of Venice Arsenale. J. Multi-Crit. Decis. Anal. 17, 85-99. DOI: $10.1002 /$ mcda.455

International Council on Monuments and Sites ICOMOS (1964), "International Charter for the Conservation and Restoration of Monuments and Sites”, The Venice Charter, http://www.international.icomos.org/charters/venice_e.pdf

Karatasios, I., Theoulakis, P., Kalagri, A., Sapalidis, A., Kilikoglou, V. 2009. Evaluation of consolidation treatment of marly limestones used in archaeological monuments. Construction and Building Materials 23, 2803-2812. doi:10.1016/j.conbuildmat.2009.03.001

Kioussi, A., Karoglou, M., Labropoulos, K., Bakolas, A., Moropoulou, A. 2013. Integrated documentation protocols enabling decision making in cultural heritage protection. Journal of Cultural Heritage 14S, e141-e146.

Martelli Castaldi, M. 2007. New criteria for the maintenance of cultural heritage. In: VarolliPiazza, R. (ed.) Sharing conservation decisions, ICCROM, Rome, Italy, 97-101. http://www.iccrom.org/ifrcdn/pdf/ICCROM_15_SharingConservDecisions-lt_en.pdf Accessed 22 June 2017

Mauko Pranjić, A., Ranogajec, J., Škrlep, L., Sever Škapin, A., Vučetić, S., Malovrh Rebec, K., Turk, J., 2018. Life cycle assessment of novel consolidants and a photocatalytic suspension for the conservation of the immovable cultural heritage. Journal of Cleaner Production 181, 293-308. https://doi.org/10.1016/j.jclepro.2018.01.087

Muñoz Viñas, S., Contemporary Theory of Conservation, Routledge, 2011.

Reyes, J., Corvo, F., Espinosa-Morales, Y., Dzul, B., Perez, T., Valdes, C., Aguilar, D., Quintana, P., 2011. Influence of Air Pollution on Degradation of Historic Buildings at the Urban Tropical Atmosphere of San Francisco de Campeche City, México. In Chmielewski, A. (ed), Monitoring, Control and Effects of Air Pollution, 201-226. DOI: 10.5772/18739. 
Sasse, H. R., and Snethlage, R.. 1997. Methods for the evaluation of stone conservation treatments. In Saving Our Architectural Heritage: The Conservation of Historic Stone Structures; Report of the Dahlem Workshop on Saving Our Architectural Heritage, The Conservation of Historic Stone Structures, Berlin, March 3-8, 1996, ed. N. S. Baer and R. Snethlage, 223-44. Dahlem Workshop Reports. Chichester and New York: John Wiley \& Sons.

Sierra-Fernandez, A., Gomez-Villalba, L.S., Rabanal, M.E., Fort, R. 2017. New nanomaterials for applications in conservation and restoration of stony materials: A review. Materiales de Construccion 67/325, 1-18. http://dx.doi.org/10.3989/mc.2017.07616.

Turk, J., Mauko Pranjić, A., Tomasin, P., Škrlep, L., Antelo, J., Favaro, M., Sever Škapin, A., Bernardi, A., Ranogajec, J., Chiurato, M., 2017. Environmental performance of three innovative calcium carbonate based consolidants used in the field of built cultural heritage. International Journal of Life Cycle Assessment, in press. doi: 10.1007/s11367-017-1260-8.

Van Saaze, V. 2013. Installation Art and the Museum: Presentation and Conservation of Changing Artworks. Amsterdam: Amsterdam University Press.

Williams, J. 2009. The role of science in the management of the UK's heritage. National Heritage Science Strategy. NHSS report 1.

Wisse, D.C.J., Brokerhof, A.W., Scholte, T. 2005. Decisions on the restoration of a Trobriand yam storehouse: the 'Decision Making Model for the Conservation and Restoration of Modern Art' applied to an ethnographic object. 14th Triennial meeting the Hague preprints vol. 1., 120-126. 


\section{Captions for figures and tables}

\section{Figures:}

Fig. 1: Scoring the criteria according to perceived level and degree of importance. Results (average scoring) are shown for all respondents (205 in total), and for conservators only (75 in total) and scientists only (55 in total).

Fig. 2: Ranking the criteria according to their relative importance. Results (average ranking) are shown for all respondents (a, 147 in total), conservators only (b, 49 in total) and scientists only (c, 38 in total).

Fig. 3: Ranking of the criteria among the different groups of stakeholders.

Fig. 4: Perception of relative importance of criteria among conservators, considering their country of origin.

Fig. 5: Perception of relative importance of criteria among scientists, considering their country of origin.

Fig. 6: The perception of relative importance of criteria among stakeholders with different environmental opinions.

\section{Tables:}

*(Tables 1 and 2 to remain in the text, Tables 3-9 to Supplementary Material Online.)*

Table 1: Evaluation criteria selected for consultation with definitions, and/or discussion of the criteria.

Table 2: Distribution of respondents in HEROMAT questionnaire according to their

Table 3: Main performance characteristics of preservative materials (protective surface coatings) and consolidants, which are considered when deciding whether to apply a certain product.

Table 4: Characteristic of preservative materials (protective surface coatings) and consolidants regarding health and safety and requirement for the use of protective equipment.

Table 5: Information on reversibility, minimum intervention and re-treatability of the materials being considered for use.

Table 6: Information regarding environmental footprint of the material.

Table 7: Information about previous experience with the material (if any).

Table 8: Information about application technique/method of the material.

Table 9: Information about the price and availability of the material. 


\section{TABLES}

Table 1: Evaluation criteria selected for consultation with definitions, and/or discussion of the criteria.

\section{Evaluation Criteria Definition}

Peer recommendation Level of previous experience with a conservation material (i.e. consolidants and preservatives). It can be practical experience shared among heritage practitioners or examples of advantages/disadvantages mentioned in the literature (reports, scientific papers, etc.).

Health and Safety Safe to handle and not dangerous for the health of workers (presuming that they wear only common/ordinary protective clothing).

Reversibility Reversibility is defined as a concept of work to a cultural heritage asset being carried out in such a way that it can be reversed at some future time, without any significant damage having being done (Forster, 2010; Andreotti et al., 2018).

Price Financial aspects are certainly important, especially when treating large surfaces of built heritage. What is expected is that it satisfies some balance between the ability of the material to work well and its price.

Availability Heritage practitioners would like to know how much time they need to wait to get a conservation material. Generally, speed is not an ally of practical built heritage conservation work. To carry out a treatment to a heritage structure, a month, or two, sooner or later, does not usually result in a significant problem.

Performance Should correspond to several requirements, which refer to durability of the characteristics consolidated stone, depth of penetration, effect on stone porosity and moisture transfer, compatibility of consolidants with stone and effect on appearance (Clifton, 1980). Depending on performance characteristics, conservation materials can be recognised as efficacious or less efficacious.

Minimum intervention A basic concept in preservation. However, there is no clear consensus among heritage practitioners about the strict meaning of this. Minimal intervention can be defined as “do as much as is necessary” or “do as little as possible” (Forster, 2010).

Application technique Consolidants are usually applied to the surface of the stone by brush or spray gun. In the case of small objects (movable cultural heritage), treatment can be carried out by pipette and immersion. The advantages and disadvantages of certain application techniques can be evaluated in terms of cost, time consumption, consolidant/preservative losses and energy consumption.

Environmental impact Any treatment of cultural heritage is related to some ecological/environmental burden. Typically Life Cycle Assessment (LCA) methods are used to evaluate environmental burdens in terms of effect on Global Warming and other impact categories (Acidification, Eutrophication, Ozone Depletion, Photochemical Oxygen Creation, Eco-toxicity etc.).

Re-treatability Means that there are no unforeseen consequences related with multiple application of consolidants/preservatives. For example, use of consolidant that blocks the pores of stone is very problematic, as it prevents subsequent application of another consolidant (Doehne and Price, 2010). 
Table 2: Distribution of respondents in HEROMAT questionnaire according to their role/position

\begin{tabular}{|c|c|c|c|c|}
\hline \multirow[b]{2}{*}{ Stakeholders } & \multicolumn{2}{|c|}{ Question 1} & \multicolumn{2}{|c|}{ Question 2} \\
\hline & $\begin{array}{c}\text { Response } \\
\text { Count }\end{array}$ & $\begin{array}{c}\text { Response } \\
\text { Percent }\end{array}$ & $\begin{array}{c}\text { Response } \\
\text { Count }\end{array}$ & $\begin{array}{c}\text { Response } \\
\text { Percent }\end{array}$ \\
\hline Conservator & 75 & 37 & 49 & 33 \\
\hline Scientist & 55 & 27 & 38 & 26 \\
\hline Engineer & 17 & 8 & 10 & 7 \\
\hline Member of the Public & 11 & 5 & 9 & 6 \\
\hline Architect & 7 & 3 & 7 & 5 \\
\hline Museum professional & 5 & 2 & 4 & 3 \\
\hline Visitor & 5 & 2 & 5 & 3 \\
\hline Industry practitioner & 4 & 2 & 1 & 1 \\
\hline Heritage manager & 3 & 2 & 2 & 1 \\
\hline Planner & 1 & 1 & 1 & 1 \\
\hline Other & 22 & 11 & 21 & 14 \\
\hline Total Answered & 205 & 100 & 147 & 100 \\
\hline
\end{tabular}


Table 3

\section{PERFORMANCE CHARACTERISTICS:}

Surface protection Yes/No

IF YES, THEN:

Photocatalytic

activity Yes/No

Hydrophobicity Yes/No

IF

ONE/BOTH

OF THEM

YES, THEN

Viscosity Numeric (mPa s)

Density Numeric (kg/l)

pH Numeric /

Durability Numeric (years)

Compatability Color

with substrate Change Yes/No

Cracking Yes/No

\section{Consolidation Yes/No}

IF YES, THEN:

Depth of

penetration Numeric (mm)

Viscosity Numeric (mPa s)

Density Numeric (kg/l)

pH Numeric /

Durability Numeric (years)

Compatability

with substrate Color Change Yes/No

Cracking Yes/No

Chemical

compatability Yes/No 
Table 4

\section{HEALTH AND SAFETY:}

\begin{tabular}{l|l}
\hline Toxicity & Yes/No \\
\hline Hazardous substance & Yes/No \\
\hline Flammability & Yes/No \\
\hline Protective equipment required & Yes/No
\end{tabular}


Table 5

3. REVERSIBILTY Yes/No

4. MINIMUM INTERVENTION Yes/No

5. RE-TREATABILITY Yes/No 
Table 6

6. ENVIRONMENTAL FOOTPRINT:

Environmental product declaration

Energy consumption

Global Warming Potential
Yes/No

Numeric (MJ/kg of product)

Numeric 
Table 7

7. PEER RECOMMENDATION Yes/No

If Yes, indicate advantages/disadvantages (description) 
Table 8

8. APPLICATION TECHNIQUE:

\begin{tabular}{|c|c|c|c|}
\hline \multirow[t]{2}{*}{ Pulp } & Yes/No & & \\
\hline & If Yes, what is the consumption & Numeric & $(\mathrm{l} / \mathrm{m} 2)$ \\
\hline \multirow[t]{2}{*}{ Spray } & Yes/No & & \\
\hline & If Yes, what is the consumption & Numeric & $(\mathrm{l} / \mathrm{m} 2)$ \\
\hline \multirow[t]{2}{*}{ Brush and roller } & Yes/No & & \\
\hline & If Yes, what is the consumption & Numeric & $(\mathrm{l} / \mathrm{m} 2)$ \\
\hline Equipment cleaning with water & Yes/No & & \\
\hline Equipment cleaning with diluter & Yes/No & & \\
\hline
\end{tabular}


Table 9

9. PRICE

Price of the conservation material

Numeric

EUR,\$.etc./litre

Other cost (special protection equipment etc.) Numeric

EUR,\$.etc

10. AVAILABILITY

Yes/No Yes/No

If Yes, what is the delivery time

Numeric

(days) 


\section{FIGURES}

a) All respondents (205)

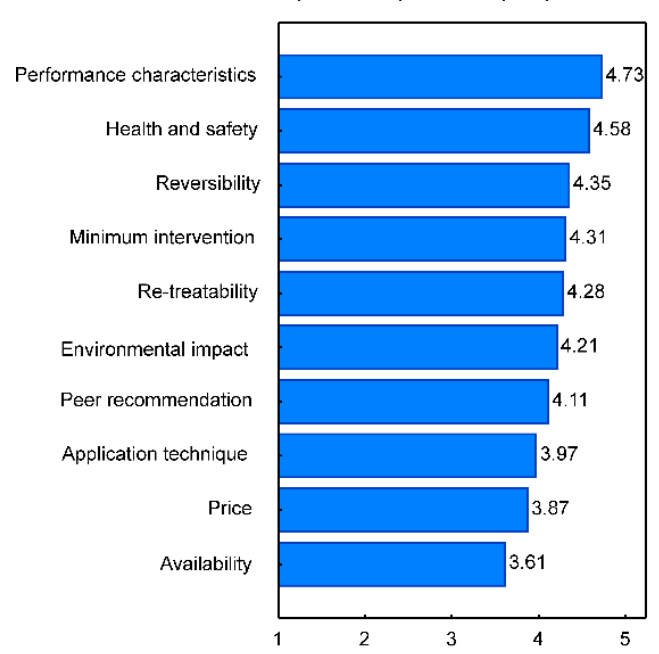

b) Conservators (75)

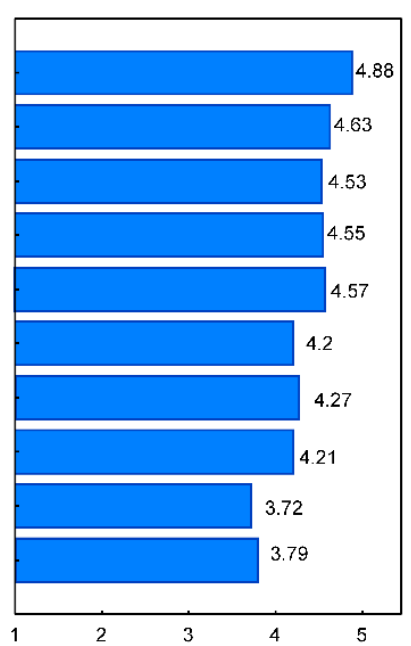

c) Scientists (55)

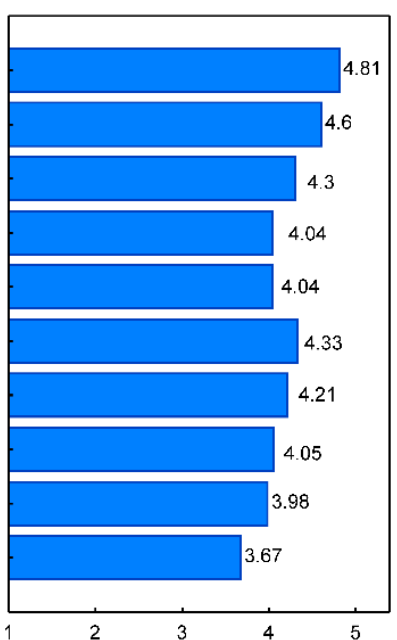

Figure 1.

a) All respondents (147)

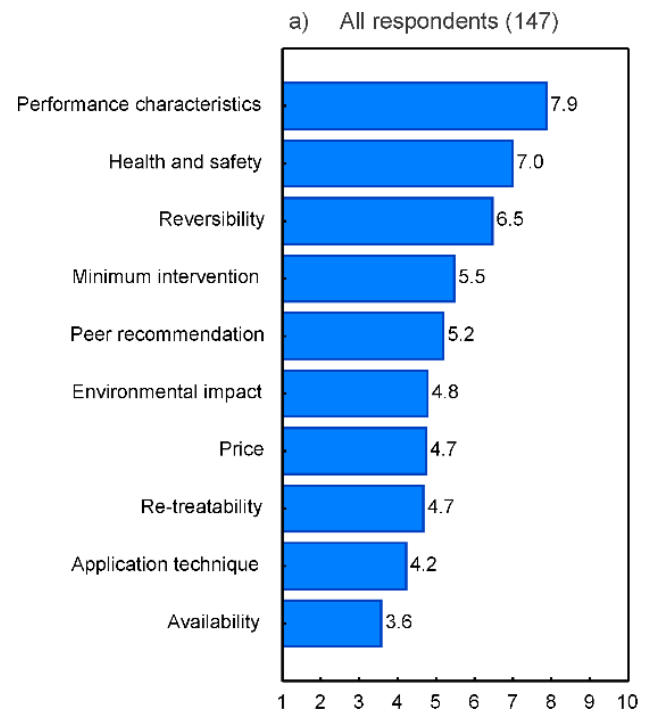

b) Conservators (49)

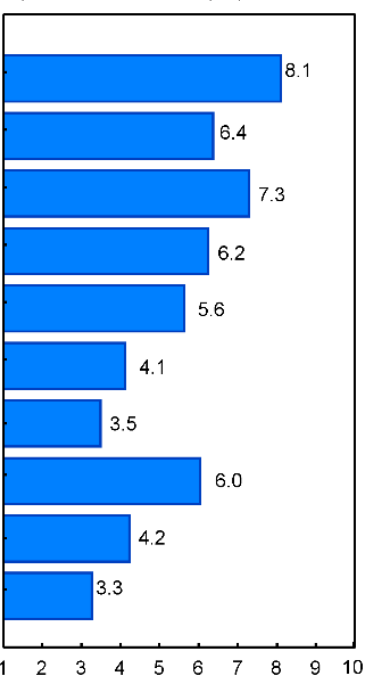

c) Scientists (38)

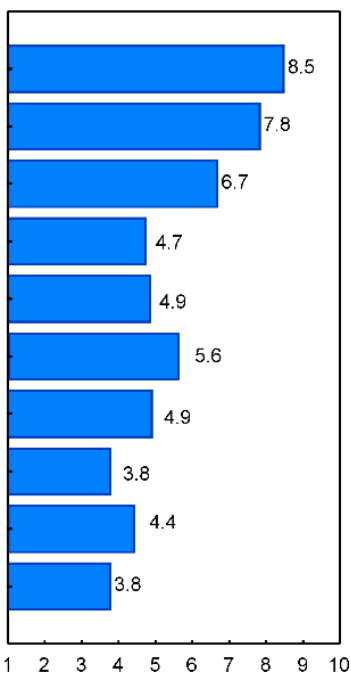

Figure 2. 


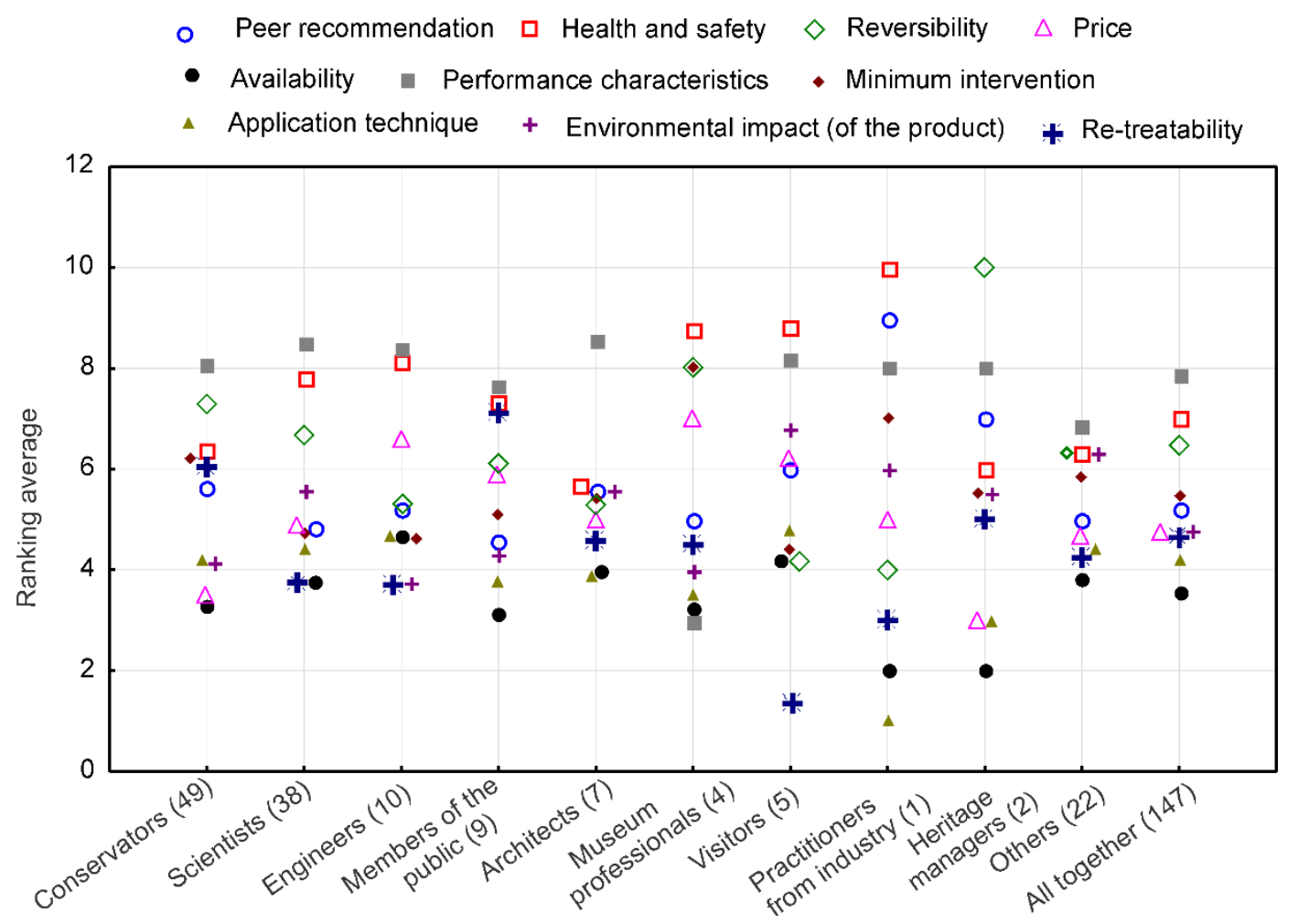

Figure 3.

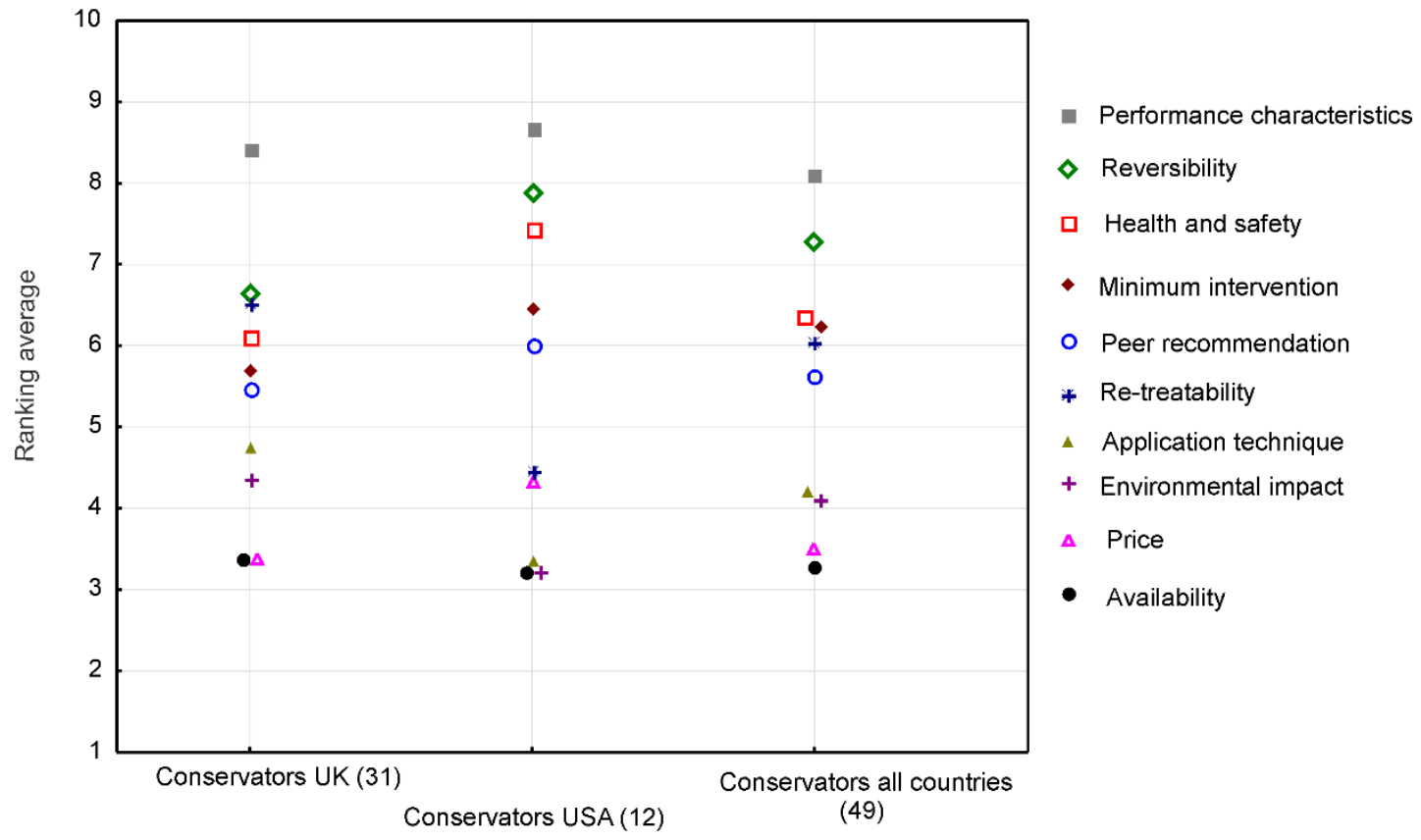

Figure 4. 


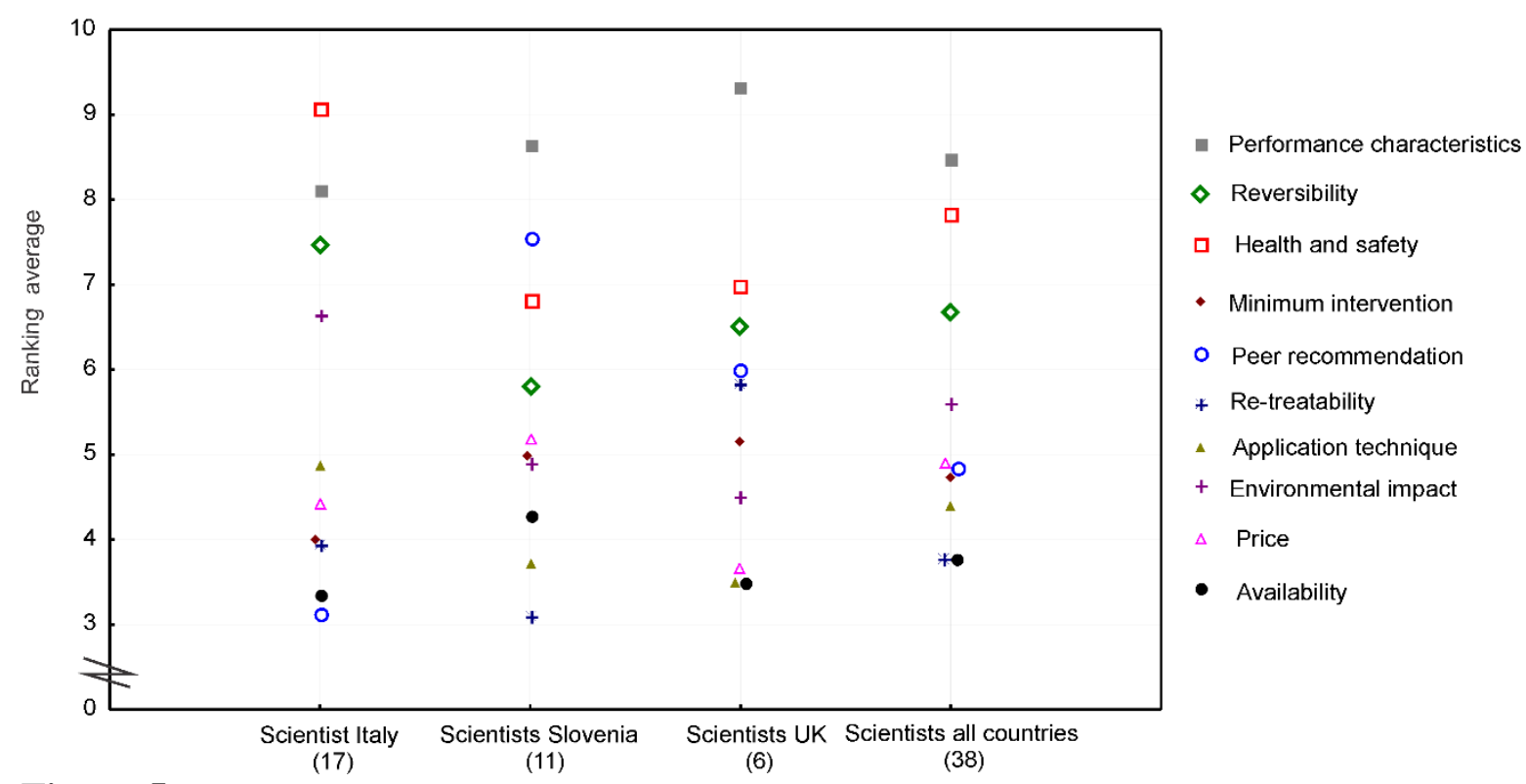

Figure 5.

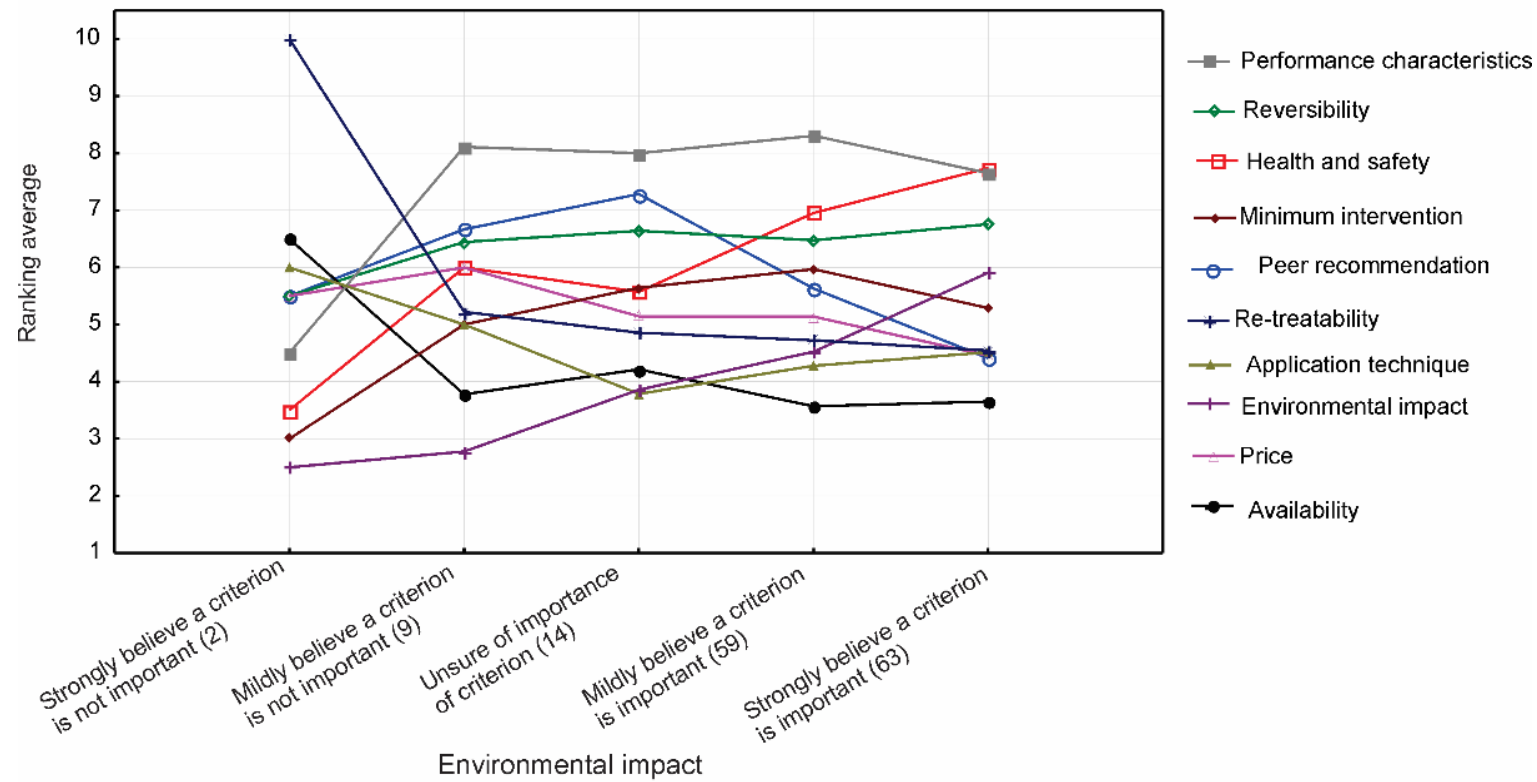

Figure 6. 